\title{
Electroconvulsive Therapy Alters Dopamine Signaling in the Striatum of Non-human Primates
}

\author{
Anne M Landau ${ }^{1,2}$, M Mallar Chakravarty ${ }^{1,3}$, Campbell M Clark ${ }^{4}$, Athanasios P Zis ${ }^{4}$ and Doris J Doudet ${ }^{*, 1,2}$ \\ 'Aarhus PET Center and Center of Functionally Integrative Neuroscience, Aarhus University Hospital, Aarhus, Denmark; ${ }^{2}$ Department of \\ Medicine/Neurology, University of British Columbia, Vancouver, BC, Canada; ${ }^{3}$ Rotman Research Institute, Baycrest Hospital and Mouse Imaging \\ Centre, Sick Children's Hospital, Toronto, ON, Canada; ${ }^{4}$ Department of Psychiatry, University of British Columbia, Vancouver, BC, Canada
}

\begin{abstract}
Electroconvulsive therapy (ECT) is one of the most effective therapies for depression and has beneficial motor effects in parkinsonian patients. However, little is known about the mechanisms of therapeutic action of ECT for either condition. The aim of this work was to explore the impact of ECT on dopaminergic function in the striatum of non-human primates. Rhesus monkeys underwent a course of six ECT treatments under a human clinical protocol. Longitudinal effects on the dopaminergic nigrostriatal system were studied over 6 weeks using the in vivo capabilities of positron emission tomography (PET). PET scans were performed prior to the onset of ECT treatments and at 24-48 h, 8-10 days, and 6 weeks after the final ECT treatment. Early increases in dopamine transporter and vesicular monoamine transporter 2 binding returned to baseline levels by 6 weeks post-ECT. Transient increases in DI receptor binding were also observed, whereas the binding potential to D2 receptors was unaltered. The increase in dopaminergic neurotransmission suggested by our results may account in part for the therapeutic effect of ECT in mood disorders and Parkinson's disease. Neuropsychopharmacology (20 I I) 36, 5I I-5 I8; doi:I0.1038/npp.2010.182; published online I3 October 2010
\end{abstract}

Keywords: dopamine I receptor; dopamine 2 receptor; dopamine transporter; electroconvulsive therapy; positron emission tomography; vesicular monoamine transporter 2

\section{INTRODUCTION}

Clinical depression is estimated to debilitate 121 million people globally. Of these individuals, $20-40 \%$ are resistant to pharmacological antidepressant treatments whereas another third show poor response. In contrast, electroconvulsive therapy (ECT) has had equal or better treatment outcomes than pharmacological approaches (Kho et al, 2003; Pagnin et al, 2004; UK ECT Review Group, 2003). Newer forms of brain stimulation such as transcranial magnetic stimulation, deep brain stimulation, and vagal nerve stimulation have emerged as potential alternate treatments for refractory patients. Among these brain stimulation approaches, ECT therapeutic parameters are the best established (Fink, 2001; Pagnin et al, 2004). Although ECT has a high safety profile, has few contraindications, and is associated with very low morbidity and mortality, it is mostly utilized in treatment-resistant

\footnotetext{
*Correspondence: Dr DJ Doudet, Department of Medicine/Neurology, University of British Columbia, 2221 Wesbrook Mall, Purdy Pavilion M36, Vancouver, BC, V6T 2B5, Canada, Tel: + 604822 7I 63, Fax: + 604822 7866, E-mail: ddoudet@interchange.ubc.ca Received 3 July 20 10; revised 24 August 20 I0; accepted II September 2010
}

population, because it is associated with consistent, mostly transient, memory disturbances in some subjects (Rami-Gonzalez et al, 2001).

ECT is based on the administration of unilaterally or bilaterally applied electric shocks to induce short-term generalized seizures. Although the therapeutic efficacy stems from seizure generation, the actual mechanisms responsible, and especially the neurotransmitters involved, are still poorly understood. One consistent observation in the rodent literature is enhanced monoaminergic neurotransmission (Fochtmann, 1994; Madhav et al, 2000; Smith et al, 1995; Strome et al, 2007; West and Weiss, 2010; Zis et al, 1991), an observation consistent with recent renewed attention to the antidepressant role of dopamine (DA). Indeed, the role of DA in mood disorders is drawing more attention both for its involvement in the pathogenesis of some typical symptoms of depression as well as its contribution to antidepressant effects. Two key features of depression are anhedonia and lack of motivation, which have both been linked to the brain reward system and DA in human and animals. Neuroimaging studies using SPECT have demonstrated elevated binding of iodobenzamide to the striatal $\mathrm{DA} \mathrm{D}_{2 / 3}$ receptors, suggesting lower baseline levels of DA (D'haenen and Bossuyt, 1994; Shah et al, 1997). Striatal dopaminergic activity is reduced in stressed 
individuals (Pruessner et al, 2004) and administration of DA antagonists leads to the occurrence of depressive symptoms (Willner et al, 2005), whereas DA agonists have been shown to have antidepressant actions and contribute to improved efficacy of current antidepressants (Nutt, 2006).

In addition to its antidepressant effect, there is also evidence that ECT may ameliorate the motor symptoms of Parkinson's disease (PD). PD is a debilitating neurodegenerative disorder caused by the degeneration of the DA neurons in the substantia nigra. It is characterized by a battery of motor symptoms, accompanied, in up to $40 \%$ of patients, by depressive comorbidity (Brown and Jahanshahi, 1995; Slaughter et al, 2001; Tandberg et al, 1996). In depressed PD patients receiving ECT for their depressive symptoms, a rapid amelioration of motor symptoms was observed independently and well before the antidepressant effects (Andersen et al, 1987; Faber and Trimble, 1991). This anti-parkinsonian motor outcome reinforces observations from animal models and suggests a role for DA in the mechanism of action of ECT. Neuroendocrine studies (Costain et al, 1982; Zis et al, 1996), microdialysis (McGarvey et al, 1993; Zis et al, 1992; Nomikos et al, 1991), behavioral studies of gross motor function (Strome et al, 2007) and stereotypies (Fochtmann, 1994; Green et al, 1977), molecular biology (Rosa et al, 2007), and receptorbinding assays (Barkai et al, 1990; Bergstrom and Kellar, 1979; Fochtmann et al, 1989; Strome et al, 2007), all support the hypothesis of at least some involvement of the DA system in the therapeutic effects of ECT in depression and $\mathrm{PD}$, underlining the necessity to explore the mechanism of action of ECT on DA neurotransmission.

Positron emission tomography (PET) allows the study of brain function and pharmacology in vivo. However, ethical concerns greatly reduce the feasibility of performing an extensive longitudinal study of the effects of ECT in human subjects. Human studies are limited by the number of doses of radioactive tracer(s) that can be administered in a given time frame to a given patient, and the interpretation of the data may be rendered difficult by individual patient history, including past or concurrent administration of psychoactive medications. Furthermore, ethically, one cannot administer ECT to normal subjects and thus, any observation in patients may be a combination of the effects of ECT and disease-induced alterations in brain chemistry, possibly shadowing the actual effects of ECT itself and leading to misinterpretation. Thus, as a first step, examining, in vivo, the effects of ECT in normal rhesus monkeys may lead to a more comprehensive model of its effects on DA function and help in the design of further studies in human patients.

In this report, we examine the effects of ECT on the striatal dopaminergic system. We studied the effects of a standard course of ECT on presynaptic and postsynaptic DA markers over a period of several weeks, in rhesus monkeys using the in vivo capabilities of PET. We used $\left[{ }^{11} \mathrm{C}\right] \mathrm{d}$-threo-methylphenidate $(\mathrm{MP})$ and $\left[{ }^{11} \mathrm{C}\right]+/$ - dihydrotetrabenazine (DTBZ) to study, respectively, binding to the synaptic DA transporter (DAT) and the vesicular monoamine transporter (VMAT2), whereas $\left[{ }^{11} \mathrm{C}\right]-$ SCH23390 and $\left[{ }^{11} \mathrm{C}\right]$-raclopride were used to assess the postsynaptic $\mathrm{DA} \mathrm{D}_{1}$ and $\mathrm{D}_{2 / 3}$ receptors. These tracers will provide a comprehensive evaluation of DA neurotransmission in response to ECT treatment.

\section{METHODS}

\section{Subjects}

Six older adult male rhesus monkeys (aged 16-22 years, weighing $8.5-17 \mathrm{~kg}$ ) were chosen to mimic the demographic of the human population most often receiving ECT. Each animal was healthy and had not been involved in pharmacologic studies or received any drugs, apart from those necessary for veterinary care and anesthetics, for $>5$ years. All experiments were approved by the Committee on Animal Care of the University of British Columbia.

\section{ECT}

The ECT application was performed as previously described (Strome et al, 2005). Briefly, monkeys were given ketamineHCL anesthesia (10-15 mg/kg intramuscular (IM), atropine $(0.5 \mathrm{mg} / \mathrm{kg} \mathrm{IM})$ to reduce secretions, and succinylcholine ( $1 \mathrm{mg} / \mathrm{kg}$ IM) to induce muscle relaxation, before the shock treatment. The animals were intubated to maintain airway patency, and positioned supine on a procedure table. A clinical ECT device (Thymaton, Somatics, Lake Bluff, Illinois) set to a frequency of $70 \mathrm{~Hz}$, a pulse width of $0.5 \mathrm{~ms}$, and a 0.9-A current was used to administer ECT. Electrodes were placed bilaterally on the animal's temples for maximal efficacy and increased inter-electrode distance (Sackeim et al, 1993). ECT was administered twice a week over a 3-week period for a total of six treatments by an investigator skilled in the administration of ECT (APZ). The seizure threshold was determined during the first session. The applied current starting from the second treatment was 1.5 times the threshold and further increased as needed during the following treatments to maintain at least a 20-s seizure using the stimulus duration to adjust the dose of current. The length of the motor seizure was timed. The animal awoke spontaneously after treatment, and no side effects were noted as a result of the treatment or repeated anesthesia.

\section{PET Scanning and Tracers}

Each animal received all the scans at all the time points mentioned, for a total of 16 scans over a period of several months. They received baseline PET scans in the 3-6 months preceding the initiation of ECT treatment and then 24-48 h, 8-10 days, and 6-8 weeks after the end of the course of ECT. The animal was prepared for scanning using a previously described protocol (Strome et al, 2005). Briefly, the animal was sedated (ketamine $10 \mathrm{mg} / \mathrm{kg}$ IM and atropine $0.5 \mathrm{mg} / \mathrm{kg} \mathrm{IM}$ ), and an intravenous line was inserted. The animal was intubated. A dose of sodium pentobarbital sufficient to induce about $30-40 \mathrm{~min}$ anesthesia $(7-10 \mathrm{mg}$ / $\mathrm{kg}$ IV) was administered to permit safe transport to the scanning suite and set up in the head holder. Maintenance anesthesia was continued with isoflurane (1-2\%). The monkey was positioned in the scanner prone in a stereotaxic frame, allowing the acquisition of 31 coronal slices of the head and brain with a Siemens ECAT 953-31B tomograph (reconstructed resolution: $9 \mathrm{~mm}$ FWHM). All the tracers were prepared as previously described. The first scan of the day did not occur before a minimum of 70-80 min after ketamine and pentobarbital administration. 
The minimum specific activity at injection was $500 \mathrm{Ci} /$ mmole. MP and DTBZ (4-5 mCi in $10 \mathrm{ml}$ sterile saline) were injected over $1 \mathrm{~min}$ via a Harvard pump (Doudet et al, 2006). SCH 23390 and raclopride were administered as a bolus plus infusion protocol as previously described $(2.5 \mathrm{mCi}$ in $10 \mathrm{ml}$ saline in $1 \mathrm{~min}$ followed by a slow infusion of $2.5 \mathrm{mCi}$ in $30 \mathrm{ml}$ saline over the following $59 \mathrm{~min}$ ) (Doudet et al, 2002a,b). The scans were acquired in random order, to both accommodate the radiochemistry schedule for the day and to insure that no specific bias due to scan order was introduced in the data. For all four tracers, the 2D acquisition sequences consisted of six 30-s scans, two 1-min scans, five 5-min scans, and four 7.5-min scans for a total duration of $60 \mathrm{~min}$ followed by a 15-min high-resolution 3D scan to facilitate structure identification.

\section{PET Data Analysis}

The PET analysis was performed by the manual placement of regions of interest (ROI) on four different striatal slices of the high-resolution 3D scan as previously described (Doudet et al, 2000, 2006). Each PET scan was matched to an existing T1 MRI scan (performed as part of other studies and acquired in the same headholder) for each animal, and a well-characterized MRI-based template consisting of multiple small ROIs was placed on each scan of each animal. The position of the striatal ROIs was adjusted based on the individual animal's neuroanatomy and radioactivity within a region and covered total striatum (four slices) and left and right caudate nucleus (three slices) and putamen (four slices). Large ROIs in two consecutive slices were placed over cerebellum, an area of non-specific accumulation. The ROIs were then transferred to the kinetic data set, and time-activity curves were obtained for each ROI and averaged for each animal into cerebellum and left and right striatum, caudate, and putamen.

Data analysis was performed using Logan graphical analysis for reversible tracer using the cerebellum as the input function for all four tracers. The slope of the plotted data from 30-60 min provided the distribution volume ratio $\mathrm{DVR}=\mathrm{BP}_{\mathrm{ND}}+1$. Data were analyzed as $\mathrm{BP}_{\mathrm{ND}}(\mathrm{DVR}-1)$.

\section{Statistics}

Statistical analysis was done with a multivariate repeated measures method, with orthogonal polynomials using SPSS v12.0 software. Briefly, this analysis involves performing a one-way analysis of variance with Time as the within term, and then partitioning the Time effect into three orthogonal polynomials to test for linear, quadratic, and cubic effects. A significant linear effect would indicate a steady increase or decrease over time post-ECT and for these data, was tested by the contrast $(-3,-1,1,3)$. A significant quadratic effect is consistent with a 'U-shaped' curve over time and for these data were tested by the contrast $(1,-1,-1,1)$. Specifically, this contrast determines whether there is a sharp rise or decrease in binding after ECT and whether the values return to baseline over time. Finally, a significant cubic effect suggests tracer-binding fluctuation over time and is tested by the contrast $(-1,3,-3,1)$. This contrast if significant would suggest an $\mathrm{N}$-shaped curve over time. Given this shape, we would conclude that a significant effect could not be attributed to ECT per se but to an extraneous factor.

To ensure that our results were consistent with previous reports on DA D1 receptor binding and ECT, a one-tailed, paired Student's $t$-test was done comparing the baseline with the first post-ECT observation $(24-48 \mathrm{~h})$.

\section{RESULTS}

As previously demonstrated, applied current and seizure length were significantly negatively correlated (Strome et al, 2005). ECT treatment induced significant increases in MP and DTBZ (DAT and VMAT2) binding in all striatal areas (Figure 1). Significant quadratic effects were observed over time, as the observed increases in binding after ECT returned toward baseline values by the time of the final scan. The F-values for the quadratic effects ranged from 8.5 to 10.75 (critical $F_{1,7}=5.59, p<0.05$ ) for the DAT and from 5.95 to 7.9 (critical $\mathrm{F}_{1,7}=5.59, p<0.05$ ) for the VMAT2 (Table 1). In addition, a significant cubic effect $(\mathrm{F}=7.10$, $p<0.05$ ) was found for the caudate for D1 tracer SCH23390. This effect was not found for any other region and suggested fluctuations in binding that could not be attributed directly to the ECT treatment. Figure 2 shows the estimated marginal means from the statistical analysis for a representative region (striatum) for all four tracers.

The further analysis performed on the SCH23390 data, based on the consistent observation in multiple studies of acute increase in DA D1 binding in rodents (Sershen et al, 1991; Strome et al, 2007; Bergstrom and Kellar, 1979; Nowak and Zak, 1989) demonstrated a significant increase in the striatal regions $(p<0.05)$ between the baseline and the acute $(24-48 \mathrm{~h})$ time point post-ECT. However, as mentioned above, this change was not consistent over later time.

\section{DISCUSSION}

Our data show that monkeys treated with a short clinical course of ECT (six sessions only) demonstrate significant alterations in dopaminergic presynaptic neurotransmission, following a quadratic ('inverted U' shape) function returning to baseline within 6 weeks after the final ECT treatment. In our study, for practical reasons (unilateral ECT would lead to short inter-electrode distances), monkeys received bilateral ECT, which is still considered the most therapeutically effective administration method (Sackeim et al, 1993) and the one most likely to induce significant changes. This protocol induced a significant decrease in the binding of a tracer of the 5HT2 receptors (Strome et al, 2005), consistent with antidepressant effect and increased interstitial serotonin (Zis et al, 1992). Thus, our ECT protocol was effective and sufficient to induce clinically relevant changes.

Dysfunctions of the presynaptic DA system are not uncommonly reported in mood disorders. In patients with major depression, DAT binding is reduced in the striatum, substantia nigra, thalamus, and anterior cingulate, with no alterations to limbic and cortical areas (Meyer et al, 2001; Remy et al, 2005). A reduction in DAT binding was also found in anhedonic depressed patients (Sarchiapone et al, 2006). Untreated symptomatic depressed patients suffering 
Methylphenidate

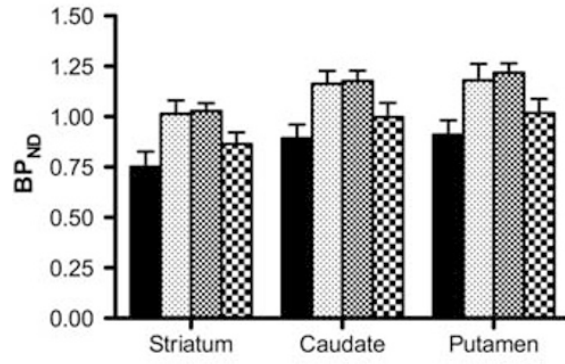

Dihydrotetrabenazine

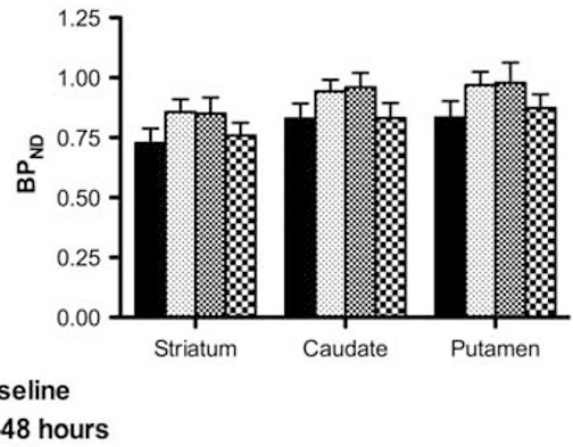

\section{SCH23390 8-10 days $\quad$ Raclopride}
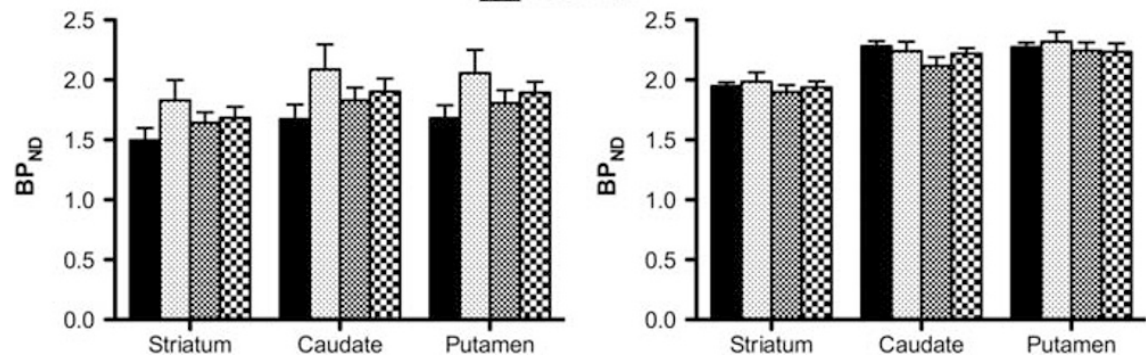

Figure I Graphs showing the binding potentials $\left(\mathrm{BP}_{\mathrm{ND}}\right)$ for the presynaptic (methylphenidate (DAT) and dihydrotetrabenazine (VMAT2)) and postsynaptic (SCH23390 (DA DI) and raclopride (DA D2)) tracers at baseline, I-2 days, 8-10 days, and 6 weeks after the end of a course of ECT. Note the quadratic shape of the response of the presynaptic tracers (inverted $U$ shape).

Table I Polynomial Contrasts to Determine the Pattern of the Changes in DA Markers After a Course of Electroconvulsive Therapy

\begin{tabular}{|c|c|c|c|}
\hline & F linear & F quadratic & F cubic \\
\hline \multicolumn{4}{|c|}{ Methylphenidate (tracer of DAT) } \\
\hline Striatum & 1.38 & $10.745^{\mathrm{a}}$ & 0.23 \\
\hline Caudate & 0.88 & $9.77^{\mathrm{a}}$ & 0.05 \\
\hline Putamen & 1.47 & $8.59^{\mathrm{a}}$ & 0.13 \\
\hline \multicolumn{4}{|c|}{ Dihydrotetrabenazine (tracer of VMAT2) } \\
\hline Striatum & 0.86 & $7.61^{\mathrm{a}}$ & 0.28 \\
\hline Caudate & 0.05 & $6.96^{\mathrm{a}}$ & 1.26 \\
\hline Putamen & 0.21 & $7.75^{\mathrm{a}}$ & 0.69 \\
\hline \multicolumn{4}{|c|}{ SCH23390 (tracer of DI) } \\
\hline Striatum & 0.79 & 2.62 & 3.69 \\
\hline Caudate & 1.89 & 2.67 & $7.10^{\mathrm{a}}$ \\
\hline Putamen & 0.61 & 1.29 & 1.87 \\
\hline \multicolumn{4}{|c|}{ Raclopride (tracer of D2) } \\
\hline Striatum & 0.81 & 0.02 & 1.92 \\
\hline Caudate & 5.14 & 1.43 & 0.94 \\
\hline Putamen & 0.57 & 0.27 & 1.29 \\
\hline
\end{tabular}

${ }^{a}$ Brain regions showing a significant effect $(p<0.05)$.

from seasonal affective disorder display a $12 \%$ decrease in striatal DAT binding (Neumeister et al, 2001). Deficits in VMAT function have been implicated in depression as well. It has been known for over 50 years that reserpine, an irreversible VMAT2 blocker, can induce depressive symptoms in patients (Freis, 1954). Experimental rodent models in which VMAT2 levels are reduced (by 50-95\%), demonstrate depressive symptoms (Schwartz et al, 2003), which can be ameliorated by acute antidepressant therapy (Fukui et al, 2007). In normal rats, exposure to repeated swim stress (a chronic stress model of depression) resulted in over a $20 \%$ reduction in striatal VMAT2 density (Zucker et al, 2005).

As DA, DAT, and VMAT2 expression are decreased in depression, and addition of drugs with DA-like properties improves the outcomes of antidepressant therapies, we hypothesized that the effect of a highly effective antidepressant such as ECT would be associated with an increase in DA synthesis and release. Our hypothesis is supported by our findings of increased MP and DTBZ binding found up to 10 days after the end of a course of ECT. It is consistent with the multiple observations in humans and rodents that ECT increases DA-mediated responses (Andersen et al, 1987; Costain et al, 1982; Rudorfer et al, 1988; Fochtmann, 1994), the existence of a therapeutic motor effect in PD patients (Douyon et al, 1989) and the efficacy of ECT as an antidepressant (Nutt, 2006). The DAT is a presynaptic transporter and has an important role in regulating striatal DA transmission. It is known to be a highly regulated protein that shows compensatory changes in protein density in response to pathological or pharmacological perturbations (Lee et al. 2000; Gordon et al, 1996). The tracer used in our study, MP, binds preferentially to the DAT but has some affinity for the noradrenaline transporter sites. As previous studies in rodents and baboons demonstrated the presence of DA terminals to be mostly in the striatum, whereas 

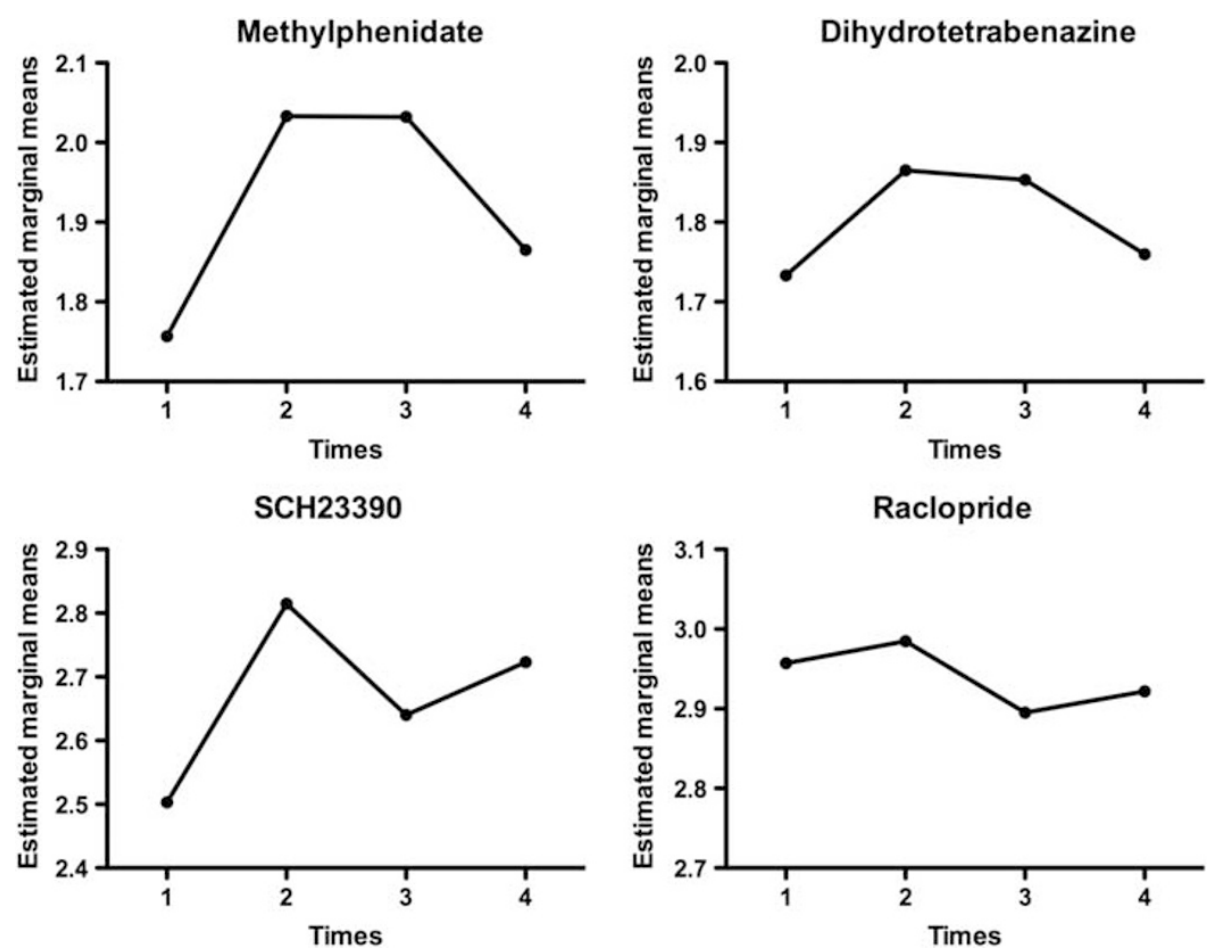

Figure 2 Graphs showing the estimated marginal means obtained from the statistical analysis for the striatum with all four tracers. The $x$ axis shows the four times considered in the analysis: I = baseline pre-ECT, $2=1-2$ days, $3=8-10$ days, and $4=6$ weeks post-ECT. Note the inverted $U$ shape for MP and DTBZ.

noradrenergic fibers are typically found in the cortex (Donnan et al, 1989; Ding et al, 1995), it can be assumed that the changes in striatal binding of MP in this study can be attributed to compensatory increases in the expression of the DAT in response to increased DA release.

Like MP, DTBZ is not uniquely specific for DA and labels the vesicular monoamine transporter type 2 located in the $\mathrm{DA}$, serotonin, and noradrenaline neurons. As the majority ( $>90 \%$ ) of the monoaminergic striatal sites are DA, our data in normal monkeys mainly reflect changes in striatal DA storage sites. Unlike DAT, VMAT2 has been long believed to be resistant to compensatory regulatory changes, reflecting terminal density (Sossi et al, 2007), but recent studies suggest that DTBZ binding may be sensitive to competing intravesicular DA (Tong et al, 2008). Increased DA release would thus lead to both reduced vesicular concentrations and increased DTBZ binding, consistent with amplified DA release. This is, to our knowledge, the first paper that directly examines the effects of ECT on presynaptic DA transmission.

There are, however, numerous animal studies, mainly in rodents, which have examined the postsynaptic consequences of ECT. The behavioral increases in DA-mediated behaviors and stereotypies have long been believed to be the result of increased responsiveness of postsynaptic DA receptors. Receptor-binding studies to examine the biochemical changes underlying these behaviors have yielded variable results. In summary, using both homogenate and autoradiographic receptor-binding techniques, the typical changes are upregulation of $D_{1}$ receptors in the normal substantia nigra and striatum after a course of ECS, whereas $\mathrm{D}_{2}$ receptors are mostly unchanged in the striatum, and $\mathrm{D}_{3}$ receptors are upregulated in the nucleus accumbens (Barkai et al, 1990; Fochtmann, 1994; Lammers et al, 2000; Nowak and Zak, 1989; Sershen et al, 1991; Smith et al, 1995; Strome et al, 2007).

Based on these observations and the report that acutely depressed patients display a $13 \%$ reduction in D1 receptor binding in the striatum (Dougherty et al, 2006), we hypothesized that ECT would induce an increased $D_{1}$ receptor binding. We did not find a significant quadratic relationship between SCH23390 binding and time post-ECT. However, based on the published literature, we compared the binding of SCH23390 at baseline and 1-2 days after ECT and found a significant increase in binding. The lack of significant quadratic relationship may have been obscured by the large variability in the data in this small sample of animals. A posteriori investigation of the reason for this variability, pointed to the possible role of the small dose of pentobarbital (7-10 mg/kg IV) administered to the animals for the transport from the housing facility to the PET suite. Momosaki et al (2004) demonstrated that barbiturate anesthesia decreased the binding of SCH 23390 to the DA D1 receptors. Although our dose is well below the recommended anesthesia dose, it may have affected the binding of SCH23390 to the D1 receptors leading to variable underestimation in different scan days: SCH23390 was administered at various times after barbiturate administration, due to variability in animal preparation, tracer delivery times and the random execution of the various scans at the different time points to prevent bias. Nevertheless, the increase in D1 binding at 1-2 days after the end of the ECT course is in agreement with several studies in rodents showing increases in striatal DA D1 receptor binding in response to ECT (Bergstrom and Kellar, 1979; Strome et al, 2007; Nowak and Zak, 1989). 
The reason for the changes in D1 receptor expression in response to ECT is not completely understood, with some evidence supporting that increased DA D1 binding may result from increases in DA transmission. Reduction in DA concentration with the irreversible VMAT2 blocker reserpine induces decreased striatal SCH23390 binding to the DA D1 receptors in rodents, an effect that can be reversed by amphetamine, a psychostimulant that both increases DA release and blocks its reuptake by the DAT (Inoue et al, 1991). Furthermore, animal models of PD demonstrate decreased striatal D1 binding (Doudet et al, 2002b; Joyce, 1991; Marshall et al, 1989). Administration of MK-801, a NMDA antagonist, which stimulates DA release, has been found to increase D1 binding in the mouse striatum (Kobayashi and Inoue, 1993). These data are in agreement with our hypothesis of increased DA transmission after ECT. We did not examine the cortical binding of SCH23390 to avoid confounds due to its significant binding to 5HT2A receptors (up to $25 \%$ of D1 binding in cortex (Ekelund et al, 2007)), its poor signal to noise ratio and the unknown effect of pentobarbital on SCH23390 cortical binding to 5HT2A/ D1, but such studies are currently underway.

The lack of effect of ECT on DA D2 binding is superficially more difficult to interpret. Raclopride is often used as a surrogate marker of DA release (Laruelle, 2000). Raclopride is a benzamide with an affinity for the DA D2 receptors similar to that of DA and appears to be sensitive to competition with the endogenous ligand (Doudet and Holden, 2003; Dewey et al, 1993). Thus, increased DA release would lead to decreased binding. The lack of significant changes in raclopride binding after ECT in our study thus appears not to support our hypothesis. However, the fact that our studies were performed in normal animals may affect this interpretation: the changes in DA concentrations necessary to induce changes in raclopride binding are substantial (with a $1 \%$ change in binding requiring $40-$ $50 \%$ increase in extracellular DA: see Laruelle (2000) for review) and may not have been sufficient to affect raclopride binding, especially taking into account the 6$7 \%$ test-retest reproducibility over time in our C11 tracer studies. In support, administration of a therapeutic dose of $\mathrm{L}$-dopa does not induce changes in raclopride binding in normal subjects, human, rats, or monkeys (Antonini et al, 1994; Floel et al, 2008; unpublished observations).

It is remarkable that the effects of ECT on the DA system waned after a few weeks, as it raises the issue of the potential relationship between the neurochemical effects of ECT and the persistence of the therapeutic effect. Similar transient effects were observed in our study of the effects of ECT on 5HT2 receptor binding (Strome et al, 2005). Both antidepressant and anti-parkinsonian effects are usually transient, lasting in most cases weeks to months, and relapse occurs in a majority of patients within 6 months prompting the addition of pharmacological therapy or institution of ECT maintenance therapy as often a necessary addition for long-term efficacy. One can argue that the brevity of the treatment in our study, six ECT sessions only versus often 10-12 sessions required for effective antidepressant treatment may have a role in the lack of sustained effect in our study, whereas longer treatments may effectively prolong the neurochemical changes. Few studies have addressed the issue of the number of treatment versus length of antidepressant effects. Furthermore, our animals were neither depressed nor parkinsonian and one cannot ignore the compensatory capabilities of the brain when dealing with chronic diseases. Individual alterations in the neurochemical background on which ECT is applied may have a role in the large variation in the therapeutic effect and the persistence of these effects between individual subjects.

In conclusion, taken together, our findings of increased DAT and VMAT2 binding support the hypothesis of increases in DA neurotransmission as a consequence of ECT, either directly or indirectly through the cortical glutamatergic system. Although the current study in normal animals does not provide proof that the therapeutic antidepressant effects of ECT are due, even in part, to its effect on DA transmission, it raises the interesting possibility of a potential role for it. The role of DA neurotransmission in antidepressant therapeutic effects has been generally downplayed in favor of the major roles of serotonin and noradrenaline, but is gaining more recognition. In support, the addition of drugs with DA facilitating properties like buproprion or moclobemide to classical antidepressants often improves clinical outcomes (Kennedy and Rizvi, 2009). There are relatively few in vivo longitudinal imaging studies of the effects of ECT on the serotonin or noradrenaline systems in primates, human, or non-human. We have already reported an effect consistent with increased serotonin transmission in normal monkeys (Strome et al, 2005), data recently confirmed by a similar study in depressed patients (Yatham et al, 2010) and in ongoing continuation studies, we have preliminary in vivo evidence that ECT also increases brain noradrenaline in normal pigs (Doudet et al, 2010). This apparent generalized effect of ECT on all three monoaminergic systems may indeed have a role in its superior efficacy. However, studies in animal models of depression are needed to confirm the role of DA in ECT effects.

\section{ACKNOWLEDGEMENTS}

We are grateful to the staff of the UBC Animal Resource Unit for providing animal care. We thank Jessica Grant (animal health technician) for her care of the animals during the PET studies and maintenance of their well-being during the entire study. We also thank the members of the UBC/TRIUMF PET group, in particular Dr T Ruth (head, PET group), Carolyn English (PET technologist), and Salma Jivan (radiochemist). The Parkinson Society Canada and the Danish Medical Research Council funded postdoctoral salary for AML. Funding for the studies was provided by CIHR MOP 74746.

\section{DISCLOSURE}

The authors declare no conflict of interest.

\section{REFERENCES}

Andersen K, Balldin J, Gottfries CG, Granerus AK, Modigh K, Svennerholm L et al (1987). A double-blind evaluation of 
electroconvulsive therapy in Parkinson's disease with 'on-off phenomena. Acta Neurol Scand 76: 191-199.

Antonini A, Schwarz J, Oertel WH, Beer HF, Madeja UD, Leenders KL (1994). $\left[{ }^{11} \mathrm{C}\right]$-Raclopride and positron emission tomography in previously untreated patients with Parkinson's disease: influence of L-dopa and lisuride therapy on striatal dopamine D2-receptors. Neurology 44: 1325-1329.

Barkai AI, Durkin M, Nelson HD (1990). Localized alterations of dopamine receptor binding in rat brain by repeated electroconvulsive shock: an autoradiographic study. Brain Res 529: 208-213.

Bergstrom DA, Kellar KJ (1979). Effect of electroconvulsive shock on monoaminergic receptor binding sites in rat brain. Nature 278: $464-466$.

Brown R, Jahanshahi M (1995). Depression in Parkinson's disease: a psychosocial viewpoint. Adv Neurol 65: 61-84.

Costain DW, Cowen PJ, Gelder MG, Grahame-Smith DG (1982). Electroconvulsive therapy and the brain: evidence for increased dopamine-mediated responses. Lancet 2: 400-404.

D'haenen HA, Bossuyt A (1994). Dopamine D2 receptors in depression measured with single photon emission computed tomography. Biol Psychiatry 35: 128-132.

Dewey SL, Smith GS, Logan J, Brodie JD, Fowler JS, Wolf AP (1993). Striatal binding of the PET ligand ${ }^{11} \mathrm{C}$-raclopride is altered by drugs that modify synaptic dopamine levels. Synapse 13: $350-356$.

Ding YS, Fowler JS, Volkow ND (1995). Carbon-11-d-threomethylphenidate: a new PET ligand for the dopamine transporter. I: studies in the baboon brain. J Nucl Med 36: 2298-2305.

Donnan GA, Kaczmarczyk SJ, Mckenzie JS, Kalnins R, Chilco PJ, Mendelsohn FA (1989). Catecholamine uptake sitesd in mouse brain: distribution determined by $[3 \mathrm{H}]$ mazindol autoradiography. Brain Res 504: 64-71.

Doudet DJ, Dyve S, Alstrup AKO, Jakobsen S, Simonsen M, Moller A et al (2010). Noradrenaline release: potential antidepressant mechanism of brain stimulation? NeuroImage 52: S47.

Doudet DJ, Holden JE (2003). Raclopride studies of dopamine release: dependence on presynaptic integrity. Biol Psychiatry 53: 1193-1199.

Doudet DJ, Holden JE, Jivan S, McGeer EG, Wyatt RJ (2000). In vivo PET studies of the dopamine $\mathrm{D} 2$ receptors in rhesus monkeys with long-term MPTP-induced parkinsonism. Synapse 38: $105-113$

Doudet DJ, Jivan S, Ruth TJ, Holden JE (2002a). Density and affinity of the dopamine D2 receptors in aged symptomatic and asymptomatic MPTP-treated monkeys: PET studies with $\left[{ }^{11} \mathrm{C}\right] \mathrm{ra}$ clopride. Synapse 44: 198-202.

Doudet DJ, Jivan S, Ruth TJ, Wyatt RJ (2002b). In vivo PET studies of the dopamine D1 receptors in rhesus monkeys with long-term MPTP-induced parkinsonism. Synapse 44: 111-115.

Doudet DJ, Rosa-Neto P, Munk OL, Ruth TJ, Jivan S, Cumming P (2006). Effect of age on markers for monoaminergic neurons of normal and MPTP-lesioned rhesus monkeys: a multi-tracer PET study. NeuroImage 30: 26-35.

Dougherty DD, Bonab AA, Ottowitz WE, Livni E, Alpert NM, Rauch SL et al (2006). Decreased striatal D1 binding as measured using PET and [ $\left.{ }^{11} \mathrm{C}\right] \mathrm{SCH} 23390$ in patients with major depression with anger attacks. Depress Anxiety 23: 175-177.

Douyon R, Serby M, Klutchko B, Rotrosen J (1989). ECT and Parkinson's disease revisited: a 'naturalistic' study. Am J Psychiat 146: 1451-1455.

Ekelund J, Slifstein M, Narendran R, Guillin O, Belani H, Guo NN et al (2007). In vivo DA D1 receptor selectivity of NNC 112 and SCH 23390. Mol Imaging Biol 9: 117-125.

Faber R, Trimble MR (1991). Electroconvulsive therapy in Parkinson's disease and other movement disorders. Mov Disord 6: 293-303.
Fink M (2001). Convulsive therapy: a review of the first 55 years. J Affect Disord 63: 1-15.

Floel A, Garraux G, Xi B, Breitenstein C, Knecht S, Herscovitch P et al (2008). Levodopa increases memory encoding and dopamine release in the striatum in the elderly. Neurobiol Aging 29: $267-279$.

Fochtmann LJ (1994). Animal studies of electroconvulsive therapy: foundations for future research. Psychopharmacol Bull 30: 321-344.

Fochtmann LJ, Cruciani R, Aiso M, Potter WZ (1989). Chronic electroconvulsive shock increases D-1 receptor binding in rat substantia nigra. Eur J Pharmacol 167: 305-306.

Freis ED (1954). Mental depression in hypertensive patients treated for long periods with large doses of reserpine. $N$ Engl J Med 251: 1006-1008.

Fukui M, Rodriguiz RM, Zhou J, Jiang SX, Phillips LE, Caron MG et al (2007). Vmat2 heterozygous mutant mice display a depressive-like phenotype. J Neurosci 27: 10520-10529.

Gordon I, Weizman R, Rehavi M (1996). Modulatory effect of agents active in the presynaptic dopaminergic system on the striatal dopamine transporter. Eur J Pharmacol 298: 27-30.

Green AR, Heal DJ, Grahame-Smith DG (1977). Further observations on the effect of repeated electroconvulsive shock on the behavioural responses of rats produced by increases in the functional activity of brain 5-hydroxytryptamine and dopamine. Psychopharmacology 52: 195-200.

Inoue O, Tsukada H, Yonezawa H, Suhara T, Langstrom B (1991). Reserpine-induced reduction of in vivo binding of SCH 23390 and N-methylspiperone and its reversal by d-amphetamine. Eur J Pharmacol 197: 143-149.

Joyce JN (1991). Differential response of striatal dopamine and muscarinic cholinergic receptor subtypes to the loss of dopamine. I. Effects of intranigral or intracerebroventricular 6hydroxydopamine lesions of the mesostriatal dopamine system. Exp Neurol 113: 261-276.

Kennedy SH, Rizvi S (2009). Emerging drugs for major depressive disorder. Expert Opin Emerg Drugs 14: 439-453.

Kho KH, Van Vreeswijk MF, Simpson S, Zwinderman AH (2003). A meta-analysis of electroconvulsive therapy efficacy in depression. J ECT 19: 139-147.

Kobayashi K, Inoue O (1993). An increase in the in vivo binding of [3H]SCH 23390 induced by MK-801 in the mouse striatum. Neuropharmacology 32: 341-348.

Lammers CH, Diaz J, Schwartz JC, Sokoloff P (2000). Selective increase of dopamine D3 receptor gene expression as a common effect of chronic antidepressant treatments. Mol Psychiatry 5: 378-388.

Laruelle M (2000). Imaging synaptic neurotransmission with in vivo binding competition techniques: a critical review. J Cereb Blood Flow Metab 20: 423-452.

Lee CS, Samii A, Sossi V, Ruth TJ, Schulzer M, Holden JE et al (2000). In vivo positron emission tomographic evidence for compensatory changes in presynaptic dopaminergic nerve terminals in Parkinson's disease. Ann Neurol 47: 493-503.

Madhav TR, Pei Q, Grahame-Smith DG, Zetterstrom TS (2000). Repeated electroconvulsive shock promotes the sprouting of serotonergic axons in the lesioned rat hippocampus. Neuroscience 97: 677-683.

Marshall JF, Navarrette R, Joyce JN (1989). Decreased striatal D1 binding density following mesotelencephalic 6-hydroxydopamine injections: an autoradiographic analysis. Brain Res 493: 247-257.

McGarvey KA, Zis AP, Brown EE, Nomikos GG, Fibiger HC (1993). ECS-induced dopamine release: effects of electrode placement, anticonvulsant treatment and stimulus intensity. Biol Psychiatry 34: $152-157$.

Meyer J, Kruger S, Wilson A, Christensen BK, Goulding VS, Schaffer A et al (2001). Lower dopamine transporter binding 
potential in striatum during depression. NeuroReport 12: 4121-4125.

Momosaki S, Hatano K, Kawasumi Y, Kato T, Hosoi R, Kobayashi $\mathrm{K}$ et al (2004). Rat-PET study without anesthesia: anesthetics modify the dopamine D1 receptor binding in rat brain. Synapse 54: 207-213.

Neumeister A, Willeit M, Praschak-Rieder N, Asenbaum S, Stastny J, Hilger E et al (2001). Dopamine transporter availability in symptomatic depressed patients with seasonal affective disorder and healthy controls. Psychol Med 31: 1467-1473.

Nomikos GG, Zis AP, Damsma G, Fibiger HC (1991). Electroconvulsive shock produces large increases in interstitial concentrations of dopamine in the rat striatum: an in vivo microdialysis study. Neuropsychopharmacol 4: 65-69.

Nowak G, Zak J (1989). Repeated electroconvulsive shock (ECS) enhances striated D-1 dopamine receptor turnover in rats. Eur J Pharmacol 167: 307-308.

Nutt DJ (2006). The role of dopamine and norepinephrine in depression and antidepressant treatment. J Clin Psychiatry 67(Suppl 6): 3-8.

Pagnin D, deQueioz V, Pini S, Cassano GB (2004). Efficacy of ECT in depression: a meta-analytic review. J ECT 20: 13-20.

Pruessner JC, Champagne F, Meaney MJ, Dagher A (2004). Dopamine release in response to a psychological stress in humans and its relationship to early life maternal care: a positron emission tomography study using $\left[{ }^{11} \mathrm{C}\right]$ raclopride. J Neurosci 24: 2825-2831.

Rami-Gonzalez L, Bernardo M, Boget T, Salamero M, Gil-Verona JA, Junque C (2001). Subtypes of memory dysfunction associated with ECT: characteristics and neurobiological bases. J ECT 17: 129-135.

Remy P, Doder M, Lees A, Turjanski N, Brooks D (2005). Depression in Parkinson's disease: loss of dopamine and noradrenaline innervation in the limbic system. Brain 128: 1314-1322.

Rosa DVF, Souza RP, Souza BR, Motta BS, Caetano F, Jornada LK et al (2007). DARPP-32 expression in rat brain after electroconvulsive stimulation. Brain Res 1179: 35-41.

Rudorfer M, Risby E, Hsiao J, Linnoila M, Potter WZ (1988). ECT alters human monoamines in a different manner from that of antidepressant drugs. Psychopharmacol Bull 24: 396-399.

Sackeim HA, Prudic J, Devanand DP, Kiersky JE, Fitzsimons L, Moody BJ et al (1993). Effects of stimulus intensity and electrode replacement on the efficacy and cognitive effects of electroconvulsive therapy. $N$ Engl J Med 328: 839-846.

Sarchiapone M, Carli V, Camardese G, Cuomo C, Di Giuda D, Calcagni ML et al (2006). Dopamine transporter binding in depressed patients with anhedonia. Psychiatry Res 147: 243-248.

Schwartz K, Yadid G, Weizman A, Rehavi M (2003). Decreased limbic vesicular monoamine transporter 2 in a genetic rat model of depression. Brain Res 965: 174-179.

Sershen H, Wolinsky T, Douyon R, Hashim A, Wiener HL, Lajtha A et al (1991). The effects of electroconvulsive shock on dopamine1 and dopamine-2 receptor ligand binding activity in MPTP-treated mice. J Neuropsychiatry Clin Neurosci 3: 58-63.

Shah PJ, Ogilvie AD, Goodwin GM, Ebmeier KP (1997). Clinical and psychometric correlates of dopamine D2 binding in depression. Psychol Med 27: 1247-1256.
Slaughter JR, Slaughter KA, Nichols DE, Holmes SE, Martens MP (2001). Prevalence, clinical manifestations, etiology, and treatment of depression in Parkinson's disease. J Neuropsychiatry Clin Neurosci 13: 187-196.

Smith S, Lindefors N, Hurd Y, Sharp T (1995). Electroconvulsive shock increases dopamine D1 and D2 receptor mRNA in the nucleus accumbens of the rat. Psychopharmacology (Berl) 120: 333-340.

Sossi V, Holden JE, Topping GJ, Camborde ML, Kornelsen RA, McCormick SE et al (2007). In vivo measurement of density and affinity of the monoamine vesicular transporter in a unilateral 6-hydroxydopamine rat model of PD. J Cereb Blood Flow Metab 27: 1407-1415.

Strome EM, Clark C, Zis AP, Doudet DJ (2005). Electroconvulsive shock decreases binding to 5HT2 receptors in non-human primates: an in vivo PET study with [18]-setoperone. Biol Psychiatry 57: 1004-1010.

Strome EM, Zis AP, Doudet DJ (2007). Electroconvulsive shock enhances striatal D1 and D3 receptor binding and improves motor performance in 6-OHDA lesioned rats. $J$ Psychiatry Neurosci 32: 193-202.

Tandberg E, Larsen JP, Aarsland D, Cummings JL (1996). The occurrence of depression in Parkinson's disease. A communitybased study. Arch Neurol 53: 175-179.

Tong J, Wilson A, Boileau I, Houle S, Kish SJ (2008). Dopamine modulating drugs influence striatal $(+)-\left[{ }^{11} \mathrm{C}\right]$ DTBZ binding in rats: VMAT2 binding is sensitive to changes in vesicular dopamine concentration. Synapse 62: 873-876.

UK ECT Review Group (2003). Efficacy and safety of electroconvulsive therapy in depressive disorders: a systemic review and meta-analysis. Lancet 361: 799-808.

West CHK, Weiss JM (2010). Effects of chronic antidepressant drug administration and electroconvulsive shock on activity of dopaminergic neurons in ventral tegmentum. Int J Neuropsychopharmacol 19: 1-10.

Willner P, Hale AS, Argyropoulos S (2005). Dopaminergic mechanism of antidepressant action in depressed patients. $J$ Affect Disorders 86: 37-45.

Yatham LN, Liddle PF, Lam RW, Zis AP, Stoessl AJ, Sossi V et al (2010). Effect of electroconvulsive therapy on brain 5-HT2 receptors in major depression. Br J Psychiatry 196: 474-479.

Zis AP, Nomikos GG, Brown EE, Damsma G, Fibiger HC (1992). Neurochemical effects of electrically and chemically induced seizures: an in vivo microdialysis study in the rat hippocampus. Neuropsychopharmacol 7: 189-195.

Zis AP, Nomikos GG, Damsma G, Fibiger HC (1991). In vivo neurochemical effects of electroconvulsive shock studied by microdialysis in the rat striatum. Psychopharmacology 103: 343-350.

Zis AP, Yatham LN, Lam RW, Clark CM, Srisurapanont M, McGarvey KA (1996). Effect of stimulus intensity on prolactin and cortisol release induced by unilateral electroconvulsive therapy. Neuropsychopharmacol 15: 263-270.

Zucker M, Weizman A, Rehavi M (2005). Repeated swim stress leads to down-regulation of vesicular monoamine transporter 2 in rat brain nucleus accumbens and striatum. Eur Neuropsychopharmacol 15: 199-201. 